It is obvious that in country districts where the number of defective-sighted children is insufficient to form special classes, some provision should be made either to send them to one of those classes in the nearest town or for their teachers to receive instruction in their management.

The Council strongly endorses the recommendation of the Departmental Committee on the Causes and Prevention of Blindness "that further provision should be made by education authorities for the education in myope classes or by similar methods for children with serious defects of vision requiring such facilities, and that steps should be taken to discover these cases at such an early age as will allow of preventive measures being adopted." (Report of Department Committee, p. 53.)

The Council therefore recommends that:

(1) Children with defective sight should be examined periodically by an ophthalmic surgeon, who should prescribe the necessary treatment and educational regime.

(2) In all large centres of population special classes should be established for children with such defective sight as renders them unsuitable for ordinary school education. These classes should be associated with the ordinary elementary schools, and limited to a nominal roll of twenty children to each class.

(3) In country districts where there are not sufficient children to form a "myope class," instruction should be given to teachers and parents on the education and management of children with defective sight.*

Parents and Local Care Committees should receive advice as to the choice of occupation for the children on leaving school. $\dagger$

\title{
ANNOTATION
}

\section{Artificial Daylight}

The great advantages obtainable by the use of light, suitably altered to give results similar to daylight, both in commerce and the arts, have so far only been obtainable by two methods, both of which require a costly installation. In one of these the light is suitably modified by the use of screens, and in the other by

${ }^{*}$ The following pamphlets issued by the London County Council contain suitable instructions for teachers and parents :-

(a) Hints for Teachers of Myope Classes.

(b) Memorandum containing advice to Parents of short-sighted Children who have been recommended for admission to a Myope Class.

(c) Teaching of Children recommended by the Medical Officer for "Easy Treatment," "Oral Teaching Only," or to "Sit in the Front Row." p. 120 .

†See papers by Bishop Harman. Proc. Roy. Soc. Med., 1915, Sec. of Ophthal., 
means of reflectors. Both methods have proved successful where the results obtainable justified their installation, as in drawing offices and in the commercial matching of colours.

According to The Electrical World, attempts are now being made to deal with the problem by using spectacles made with a special glass, the invention of which is credited to Dr. Hermann Weiss, of Vienna. We presume that such a method can only be applied to some definite source of light, such as an arc lamp. If practicable it would render it possible to enjoy a picture gallery even in a November afternoon in London. It must, moreover, be remembered that methods of obtaining "artificial daylight" which depend on screens require a very powerful source of illumination, which is not only costly, but also may easily cause damage to the pictures. We look forward with interest to hearing how the inventor proposes to get over the obvious difficulties, such as the prevention of light from outside sources reaching the eye and the correct standardization of the screening medium to the various sources of light in use.

\section{ABSTRACTS}

\section{I.-HEREDITARY DISEASES}

(I) Truc (Montpellier) and Opin (Toulon).-A long-established centre of night-blindness in Provence. (Congenital familial hereditary night-blindness; the Nougaret of Vendémian type.) Arch. d'Ophtal., August, 1925.

[Readers of this communication may remember that the late Edward Nettleship and Professor Truc were associated in the investigation of the important genealogy of congenital night-blindness commonly known as the Vendémian pedigree, which was begun by Cunier and recorded by him in 1838 . The completed pedigree was published in the Transactions of the Ophthalmological Society of the United Kingdom in 1907, and in the Bulletins de la Société française d'Ophtalmologie, 1909.]

(1) Truc and Opin have discovered more or less accidentally, another centre of congenital hereditary night-blindness, with precisely similar characteristics, and have published the pedigrees of several families affected by this abnormality.

The case which first came under observation was a female, a native of Néoules, Department of Var. She informed the authors that others in her part of the country suffered from a similar disability; 